\title{
Relationships between physical activity and muscular strength among healthy adults across the lifespan
}

\author{
Allie Leblanc ${ }^{1,4^{*}}$, Beth A. Taylor ${ }^{3}$, Paul D. Thompson ${ }^{3}$, Jeffrey A. Capizzi ${ }^{3}$, Priscilla M. Clarkson², C. Michael White ${ }^{1}$ \\ and Linda S. Pescatello ${ }^{1}$
}

\begin{abstract}
The purpose of this study was to examine relationships between objective and self-report measures of physical activity and muscle strength among healthy adults ranging in age from 20 to 91 years. Participants $(n=412)$ were mostly Caucasian men (48\%) and women (52\%) $43.9 \pm 16.1$ year of age with a body mass index (BMI) of $26.4 \pm 4.8 \mathrm{~kg} / \mathrm{m}^{2}$. Physical activity was measured objectively with an accelerometer and by self-report with the Paffenbarger Physical Activity Questionnaire. Upper and lower body muscle strength were measured with an isokinetic dynamometer and handgrip strength with a static dynamometer. Multivariate regression assessed relationships between physical activity and muscle strength. The strongest correlates of upper body strength including handgrip strength were gender $(r=-0.861$ to -0.716$)$, age $(r=-0.445$ to -0.241$)$, BMI $(r=0.134-0.397)$, and physical activity $(r=0.093-0.186)$. The strongest correlates of lower body strength were gender ( $r=-0.772$ to -0.634$)$, age ( $r=-0.663$ to -0.445$)$, BMI $(r=0.160-0.266)$, and physical activity $(r=-0.139$ to 0.151$)$. The strongest correlates of muscle strength were gender (explaining $40-74 \%$ of the variance), age (6-44\%), and BMI (2-16\%), while physical activity correlations were weaker (1-3\%). Conflict surrounding the influence of a physically active lifestyle on muscle strength with age may be due to the stronger influences of other factors that supersede those of physical activity whether measured objectively or by self-report methods.
\end{abstract}

Keywords: Accelerometer, Isokinetic dynamometer, Physical activity, Muscle strength, Classification, Methods, Aging

\section{Background}

Regular participation in physical activity promotes healthy weight, bone mass, and muscle function as well as prevents falls and fractures in older adults. These and other numerous health benefits ultimately extend active life expectancy (USA Department of Health and Human Services 2008). Physical inactivity is a major determinant of the loss of muscle strength as is gender, aging, and body mass index (BMI) (Hollmann, Struder, Tagarakis, and King 2007; Hortobagyi, Katch, Katch, LaChance, and Behnke 1990; Musselman and Brouwer 2005). Maximum muscle strength is typically achieved between 20 and 30 year (Bosco and Komi 1980) and begins to decline

*Correspondence: Allie.e.leblanc@gmail.com

${ }^{4} 31$ Silversmith Rd, Unionville, CT 06085, USA

Full list of author information is available at the end of the article around an age of 40 year (Kallman, Plato, and Tobin 1990). After 70 year, overall muscle strength declines $3.6 \%$ annually for men and $2.8 \%$ for women (Goodpaster et al. 2006).

Nonetheless, the literature on relationship between physical activity and muscle strength as modulated by age is mixed. Utilizing a self-report physical activity questionnaire, (Paalanne et al. 2009) found greater maximal isometric trunk muscle strength measured by a computerized dynamometer among 874 healthy, young men and women with high levels of moderate to vigorous intensity physical activity compared to those with lower levels of physical exertion. Rantanen et al. (1997) found physical activity assessed by questionnaire positively associated with maximal isometric strength of several muscle groups evaluated by an dynamometer among 287 older adults.

\section{贷 Springer}

(c) 2015 Leblanc et al. This article is distributed under the terms of the Creative Commons Attribution 4.0 International License (http://creativecommons.org/licenses/by/4.0/), which permits unrestricted use, distribution, and reproduction in any medium, provided you give appropriate credit to the original author(s) and the source, provide a link to the Creative Commons license, and indicate if changes were made. 
Sandler et al. (1991) found physical activity as assessed by the Paffenbarger physical activity questionnaire (Paffenbarger, Wing, and Hyde 1978) positively correlated with muscle strength assessed by a dynamometer among a sample of 620 middle-aged to older women. Furthermore, these investigators found physical activity to be the second largest contributor to the variance in muscle strength $(r=0.54)$ second to age $(r=0.48)$ (Sandler et al. 1991). Forrest et al. (2007) also assessed physical activity using the Paffenbarger physical activity questionnaire (Paffenbarger et al. 1978) in a sample of about 20,000 older women and found physical activity positively associated with handgrip strength measured via dynamometry. Jakobsen et al. (Jakobsen, Rask, and Kondrup, 2010) found physical activity assessed with the Baecke questionnaire positively associated with handgrip strength in women, but not men ranging in age from 25 to 65 year. In contrast, other investigators utilizing self-report physical activity questionnaires have found no correlation with physical activity and muscle strength among older populations of men and women (Bryant, Trew, Bruce, and Cheek 2007; Daly et al. 2008). Collectively, in these studies, several investigative employed self-report questionnaires that were validated (Bryant et al. 2007; Forrest et al. 2007; Jakobsen et al. 2010; Rantanen et al. 1997; Sandler et al. 1991), while others did not (Daly et al. 2008; Paalanne et al. 2009), perhaps contributing to the inconsistencies in this literature.

Adding to these divergent findings are the two studies assessing physical activity with an accelerometer. Gerdhem et al. (Gerdhem, Dencker, Ringsberg, and Akesson, 2008) found physical activity assessed with an accelerometer did not correlate with knee extension and flexion muscle strength among 57 older women. Similarly, Morie et al. (2010) found no differences in upper body and lower extremity muscle strength between the low and high physical activity groups measured by an accelerometer among 82 older men.

Reasons for the discrepancies among studies examining the relationships between physical activity and muscle strength are unclear but could reside in the methods that were used to assess physical activity and muscle strength as well as differences in the characteristics of the population studied. Previous reports (Bryant et al. 2007; Daly et al. 2008; Forrest et al. 2007; Gerdhem et al. 2008; Jakobsen et al. 2010; Morie et al. 2010; Paalanne et al. 2009; Rantanen et al. 1997; Sandler et al. 1991) have examined either self-report or objective measures of habitual physical activity and measures of muscle strength in populations with narrow age ranges and that may have included only one gender. Additionally, examination of other factors that have been documented to influence the relationship between physical activity and muscle strength within the same study is generally lacking.

Therefore, the purpose of this study was to examine the relationships among a self-report and objective measure of physical activity and muscle strength among a large sample of healthy, men and women from 20 to 91 year to provide insights into the mixed literature.

\section{Methods}

\section{Experimental approaches to the problem}

This sub-study derived from a larger National Institutes of Health (NIH) funded study entitled, "The Effect of Statins on Skeletal Muscle Function" (STOMP) (NIH RO1 HL081893-01A2) (P. D. Thompson et al. 2010). The specific aims of STOMP were to examine the incidence rate of statin-induced muscle pain or discomfort, also known as myalgia, and the effects of statins on muscle strength, endurance, and aerobic exercise performance in a healthy population taking $80 \mathrm{mg}$ of Atorvastatin or a placebo (P. D. Thompson et al. 2010). The STOMP methods have been described in detail elsewhere (Ballard et al. 2013; Grimaldi et al. 2013; Parker et al. 2013; Stroes et al. 2015; P. D. Thompson et al. 2010). This substudy used baseline data from STOMP to examine the relationships among objective and self-report measures of physical activity and isokinetic and isometric measures of muscular strength and endurance among a population of healthy men and women $\geq 20$ year with no present or previous history of statin use (P. D. Thompson et al. 2010). STOMP was approved by the Institutional Review Board (IRB) of the participating sites that included Hartford Hospital, the University of Connecticut, and the University of Massachusetts Amherst.

All data collected for this sub-study were taken from STOMP study visits 1-3 (V1, V2, V3 respectively) prior to randomization to either a placebo or $80 \mathrm{mg}$ of Atorvastatin (P. D. Thompson et al. 2010). All data were manually entered into an electronic website maintained by the study coordinator at Hartford Hospital.

\section{Subjects}

A total of 220 men and 220 women $\geq 20$ year were recruited for STOMP and were equally distributed within three designated age categories (20-39, 40-54, 55+ year) over 4 years at the three testing sites. Recruitment strategies included local and campus newspaper advertisements, flyers, and posters (P. D. Thompson et al. 2010). Once a potential subject expressed interest, they underwent a phone interview to determine eligibility based on a strict set of exclusion criteria. Participants were excluded if they were presently or had previously been treated with cholesterol-lowering medications, or had been diagnosed with diabetes mellitus, hyper- or hypothyroidism, or any 
heart condition that required medication or a restriction of physical activity. Anyone unable to exercise vigorously on a treadmill or who had hepatic disease, renal disease, or occult cardiac ischemia documented during a physician supervised treadmill test during STOMP V1 was also excluded from the study.

Individuals using hypertensive medications were included if they had been on these medications for at least 3 months and their blood pressure (BP) was stable $(<140 / 90 \mathrm{mmHg})$. BP was monitored during V1 and V2 to ensure each subject's eligibility. Women of childbearing age were given a pregnancy test at the start and conclusion of the study and were asked to use contraception throughout the duration of their participation in the study. The population for this substudy ( $\mathrm{n}=412)$ was young, healthy Caucasian men $(\mathrm{n}=198)$ and women $(\mathrm{n}=214)$. Subjects were on average middle aged (43.9 \pm 16.1 year) and overweight $\left(26.4 \pm 4.8 \mathrm{~kg} / \mathrm{m}^{2}\right)$ and had optimal blood pressure $(118.9 \pm 13.3 / 75.3 \pm 9.7 \mathrm{mmHg})$. Men were heavier $\left(27.4 \pm 4.5 \mathrm{~kg} / \mathrm{m}^{2}\right)$ and had higher maximum oxygen consumption $\left(\mathrm{VO}_{2 \max }\right)(38.3 \pm 8.9 \mathrm{ml} / \mathrm{kg} / \mathrm{min})$ than women $\left(25.4 \pm 5.05 \mathrm{~kg} / \mathrm{m}^{2}, 30.0 \pm 8.8 \mathrm{ml} / \mathrm{kg} / \mathrm{min}\right.$ respectively) $(\mathrm{p}<0.001)$. Women had higher resting heart rate $(70.5 \pm 10.8 \mathrm{bpm})(\mathrm{p}<0.01)$ and lower blood pressure $(116.3 \pm 13.4 / 74.2 \pm 9.8 \mathrm{mmHg})$ than men $(67.3 \pm 11.8 \mathrm{bpm}, 121.8 \pm 12.7 / 76.6 \pm 9.4 \mathrm{mmHg}$ respectively) $(\mathrm{p}=0.03)$.

\section{Procedures}

\section{Anthropometric Measurements}

This sub-study used baseline anthropometrics from V1. Body weight $(\mathrm{kg})$ and height $(\mathrm{m})$ were measured using a calibrated balance beam scale and a wall mounted tape measure. BMI was then calculated $\left(\mathrm{kg} / \mathrm{m}^{2}\right)$. Waist circumference $(\mathrm{cm})$ was measured with a Gulick springloaded non-dispensable tape measure (P. D. Thompson et al. 2010). Subjects stood erect with their arms at their sides, feet together and abdomen relaxed, and a horizontal measurement was taken at the narrowest part of the torso above the umbilicus and below the xiphoid process.

\section{Muscular strength and endurance}

Muscle strength and endurance were assessed on V1, V2, and V3. Visit 1 was used to familiarize the subject with the Biodex and the handgrip dynamometer. The data from V2 and V3 were used as the muscle strength measures.

\section{Handgrip strength}

Isometric handgrip strength was assessed on the dominant hand using a handgrip dynamometer (P. D. Thompson et al. 2010). The subject performed three maximal contractions for $3 \mathrm{~s}$ each, with $1 \mathrm{~min}$ of rest between each contraction. The average of the three contractions was used as the measure of average peak torque (Nm) (P. D. Thompson et al. 2010).

\section{Lower body}

All muscle strength and endurance measures were assessed using the Biodex System 3 Isokinetic Dynamometer (Biodex Medical, Shirley, NY) (P. D. Thompson et al. 2010). Before each visit, the Biodex was calibrated following the procedures outlined by Pincivero et al. (2003) (Pincivero, Campy, and Coelho, 2003). Subjects warmed up by performing two submaximal knee extension contractions at $10 \%$, two contractions at $50 \%$, and two contractions at $90 \%$ effort (P. D. Thompson et al. 2010). Subjects were seated for all leg testing and had their arms folded across their chest and secured with Velcro straps at the thigh, pelvis, and torso to prevent extraneous movement. The lateral femoral epicondyle of the subject was aligned with the axis of rotation of the lever arm of the Biodex (P. D. Thompson et al. 2010). The dominant hand side knee was tested.

Isometric strength Subjects performed three isometric contractions at a knee angle of $110^{\circ}$. Subjects started the test by kicking out and holding this position for $4 \mathrm{~s}$ followed by a $1 \mathrm{~min}$ rest. They then pulled back as hard as they could and held this position for 1 min followed by another $1 \mathrm{~min}$ rest. This procedure was repeated until the subject had completed a total of three kicks and three pulls. They then rested for $5 \mathrm{~min}$. The average peak torque $(\mathrm{Nm})$ of each kick and pull was averaged.

Isokinetic strength Next, subjects performed five contractions at $60^{\circ} / \mathrm{s}$ by doing five full range of motion kicks as hard and as fast as they could, followed by another 5 min of rest. Subjects then performed five isokinetic contractions at $180^{\circ} / \mathrm{s}$ by doing five full range of motion kicks in the same manner. Average peak torque $(\mathrm{Nm})$ was calculated over an angular displacement of $60^{\circ}$. A 10 min rest was given prior to the dynamic muscle endurance testing.

Dynamic muscle endurance To complete the leg muscle strength assessment, participants underwent a dynamic muscle endurance test of the knee. Subjects performed 30 consecutive full range of motion maximal contractions at $180^{\circ}$ s (P. D. Thompson et al. 2010). Average peak torque $(\mathrm{Nm})$ was measured. A fatigue index was also calculated as a measure of muscle endurance as the average peak torque of the last 5 repetitions divided by the average peak torque of the 5 highest consecutive repetitions, multiplied by 100 , and then subtracted from the total of 100 (\%) (P. D. Thompson et al. 2010). 


\section{Upper body}

Upper body strength of the biceps and triceps was tested using the elbow attachment on the Biodex. Subjects were seated with their torso at $90^{\circ}$ of hip flexion and secured by a strap at the pelvis and two straps across the torso to prevent extra movements. The arm was positioned so that the axis of the level arm coincided with the rotational axis of the elbow joint in order to assure movement of the lower arm through the sagittal plane. A wide strap crossed the biceps brachii to ensure the alignment of the subjects elbow with the axis of the lever arm during testing. The subject performed two submaximal elbow flexion contractions at $10 \%$, two contractions at $50 \%$, and two contractions at $90 \%$ effort to warm up (P. D. Thompson et al. 2010).

Isometric strength Subjects performed three isometric contractions at an elbow angle of $90^{\circ} / \mathrm{s}$. Subjects started the test by pushing out and holding this position for $4 \mathrm{~s}$ followed by a $1 \mathrm{~min}$ rest. They then pulled back as hard as they could and held this position for $1 \mathrm{~min}$ followed by another $1 \mathrm{~min}$ rest. This procedure was repeated until the subject had completed three pushes and three pulls, and was then followed by $5 \mathrm{~min}$ of rest (P. D. Thompson et al. 2010). Average peak torque was measured (Nm).

Isokinetic strength Next the subject performed four isokinetic contractions at an elbow angle of $60^{\circ} / \mathrm{s}$ followed by $5 \mathrm{~min}$ of rest. Finally, the subject performed 4 isokinetic contractions at an elbow angle of $180^{\circ}$ s (P. D. Thompson et al. 2010). The average peak torque (Nm) was calculated over an angular displacement of $60^{\circ}$ (P. D. Thompson et al. 2010).

\section{Physical activity}

Accelerometer Subjects were given an Actical physical activity accelerometer (Mini Meter, a Respironics Inc., Bend, OR) to wear on the hip for 96 consecutive hr encompassing 2 week days and 3 weekend days immediately after V2 and then collected at V3 (P. D. Thompson et al. 2010). The epoch was set at $25 \mathrm{~s}$ (P. D. Thompson et al. 2010). The Actical was only removed while the subject was swimming, bathing, showering, or sleeping. The data were downloaded immediately at the following study visit (V3) to ensure that $96 \mathrm{~h}$ of useable data were collected. Activity levels were then averaged from the $96 \mathrm{~h}$ and included the following measures of physical activity: activity (counts/day), energy expenditure ( $\mathrm{kcal} / \mathrm{d}$ ), average time spent $(\mathrm{min} / \mathrm{d})$ in sedentary, light, moderate, and vigorous intensity physical activity, and steps per day. Time spent in sedentary activity was defined as $<1.5$ METs, light intensity physical activity was 1.5 to $<3.0$ METs, moderate intensity physical activity 3.0 to $<6.0$ METs, and vigorous intensity physical activity $>6.0$ METs.

Paffenbarger physical activity questionnaire The Paffenbarger physical activity questionnaire was administered by research assistants at V1 (P. D. Thompson et al. 2010). This sub-study utilized data from question 8 , which asked participants to estimate how many hours on a typical weekday and a typical weekend day during the past year they participated in activities of varying intensities. Each type of movement (i.e., sleeping or reclining, sitting, or engaging in light, moderate, and vigorous intensity physical activity) was assigned a metabolic equivalent task (MET) value (P. D. Thompson et al. 2010) and total time (h) spent in each type of movement was used to calculate $\mathrm{MET}^{*} \mathrm{hr} / \mathrm{wk}$ for each subject.

\section{Cardiorespiratory fitness}

On V2 prior to randomization, $\mathrm{VO}_{2 \max }(\mathrm{ml} / \mathrm{kg} / \mathrm{min})$ was measured using a modified Balke maximal treadmill test (American College of Sports Medicine 2013; Balke and Ware 1959; Takken et al. 2009) assessed using a breathby-breath analysis of expired gases though the Parvomedics True One 2400 Metabolic Cart (ParvoMedics Corp, Sandy, UT) (P. D. Thompson et al. 2010). The test was terminated when one or more of the following conditions was met: the subject reported an rate of perceived exertion of 18 , the subject had a respiratory exchange ratio greater than 1.1, the subject achieved their age predicted maximum heart rate, there was a plateau in $\mathrm{VO}_{2}$, or the subject self-terminated due to fatigue or discomfort (American College of Sports Medicine 2013).

\section{Statistical analyses}

The Statistical Package for the Social Sciences (SPSS) Base 18.0 for Macintosh (IBM, Armok, NY) was used to calculate all the statistics. Descriptive statistics (mean \pm SEM) were calculated for all study variables. Pearson product moment correlation coefficients $(r)$ were performed to examine the relationship between muscle strength and endurance and measures of physical activity as assessed by accelerometer or by the Paffenbarger physical activity questionnaire. Multivariate regressions were performed to assess which subject characteristics and physical activity measures were predictive of muscle strength. The variance inflation factor (VIF) was used to quantify the degree of multicollinearity of predictor variables, and any variable exceeding 3.0 was removed from the model. If variables were removed from the model due to VIF $>3.0$, which only occurred with the accelerometer models, the variable that was retained had the strongest correlation with the measure of strength and in most instances was total energy expenditure which 
encompassed the variables removed. Significance was accepted at $\mathrm{p}<0.05$.

\section{Results}

Subjects spent most (76.2 \%) of their time (min/day) being sedentary, followed by time spent in light intensity physical activity (14.4\%) and moderate intensity physical activity (9.1\%), with the least amount of time spent in vigorous intensity physical activity $(0.3 \%)$ (Table 1$)$. Study participants easily meet the recommendations for daily physical activity with an average of $131.2 \mathrm{~min} /$ day spent in moderate intensity physical activity (Table 1 ). Although there is no published standard for any of the strength measures measured in our study, compared to similar studies, our subjects approximated average muscle strength and endurance in all measures (Forrest et al. 2007; Jakobsen et al. 2010; Paalanne et al. 2009; Rantanen et al. 1997; Sandler et al. 1991), according to other comparable datasets (Forrest et al. 2007; Jakobsen et al. 2010; Paalanne et al. 2009; Rantanen et al. 1997; Sandler et al. 1991). Men were significantly stronger in every measure of muscle strength than the women $(\mathrm{p}<0.001)$ (Table 2$)$.

\section{Multivariable regression models of correlates of muscle strength and endurance}

\section{Accelerometer}

\section{Lower body}

Multivariate regression correlates of lower body muscle strength and endurance are displayed in Table 3. Factors accounting for $52.7 \%$ of the variance in isometric knee extension were gender $(\mathrm{p}<0.001)$, age $(\mathrm{p}<0.000)$, BMI $(\mathrm{p}<0.001)$, and time spent in sedentary behavior $(\mathrm{p}=0.005)$. Factors accounting for $65.6 \%$ of the variance in isokinetic knee extension at $60^{\circ} \% \mathrm{~s}$ were gender $(\mathrm{p}<0.001)$, age $(\mathrm{p}<0.001)$, BMI $(\mathrm{p}<0.001)$, and total energy expenditure $(\mathrm{p}=0.002)$. Factors accounting for $61.5 \%$ of the variance in isokinetic knee extension at $180^{\circ} / \mathrm{s}$ were gender $(\mathrm{p}<0.001)$, age $(\mathrm{p}<0.001)$, BMI $(\mathrm{p}=0.001)$, and total energy expenditure $(\mathrm{p}=0.001)$.
Finally, $74.8 \%$ of the variance in knee endurance extension was accounted for by gender $(p<0.001)$, age $(\mathrm{p}<0.001), \mathrm{BMI}(\mathrm{p}<0.001)$, and total energy expenditure $(\mathrm{p}=0.002)$. Season, test site, and $\mathrm{VO}_{2 \max }$ were not significant correlates of upper and lower body muscle strength. $(\mathrm{p}>0.05)$.

\section{Upper body}

Multivariate regression correlates of upper body muscle strength are displayed in Table 4. Factors accounting for $55.2 \%$ of the variance in handgrip strength were gender $(\mathrm{p}<0.001)$, age $(\mathrm{p}<0.001)$, and time spent in light intensity physical activity $(\mathrm{p}<0.001)$. Factors accounting for $77.2 \%$ of the variance in isokinetic elbow flexion at $60^{\circ} / \mathrm{s}$ were gender $(\mathrm{p}<0.001)$, BMI $(\mathrm{p}<0.001)$, age $(\mathrm{p}<0.001)$, and time spent in light intensity physical activity $(\mathrm{p}=0.002)$. Season, test site, and $\mathrm{VO}_{2 \max }$ were not significant correlates of upper and lower body muscle strength. $(\mathrm{p}>0.05)$.

\section{Paffenbarger physical activity questionnaire Lower body}

Multivariate regression correlates of lower body muscle strength and endurance are displayed in Table 5. Factors accounting for $53.0 \%$ of the variance in isometric knee extension were gender $(\mathrm{p}<0.001)$, age $(\mathrm{p}<0.001)$, BMI $(\mathrm{p}<0.001)$, and total self reported energy expenditure $(\mathrm{p}=0.033)$. Factors accounting for $60.6 \%$ of the variance in isometric knee flexion were gender $(\mathrm{p}<0.001)$, age $(\mathrm{p}<0.001)$, BMI $(\mathrm{p}<0.001)$, and total self reported energy expenditure $(\mathrm{p}=0.010)$. Season, test site, and $\mathrm{VO}_{2 \max }$ were not significant correlates of upper and lower body muscle strength. $(\mathrm{p}>0.05)$.

\section{Upper body}

Multivariate regression correlates of upper body muscle strength are displayed in Table 6. Factors accounting for $55.4 \%$ of the variance in handgrip strength were gender $(\mathrm{p}<0.001)$, age $(\mathrm{p}<0.001)$, BMI $(\mathrm{p}<0.01)$, and

Table 1 Measures of physical activity for the total sample and by gender (Mean \pm SD)

\begin{tabular}{|c|c|c|c|}
\hline Characteristics & Total $(n=412)$ & Men $(n=198)$ & Women $(n=214)$ \\
\hline Total steps per day & $8182.4 \pm 3537.1$ & $8448.4 \pm 3379.5$ & $7934.4 \pm 3668.7$ \\
\hline Total energy expenditure (kcal/day) & $624.6 \pm 275.1$ & $722.7 \pm 298.9^{*}$ & $531.7 \pm 212.9$ \\
\hline Actical total counts (per day) & $186699.7 \pm 104354.9$ & $203739.6 \pm 110309.5^{\psi}$ & $170724.9 \pm 95992.9$ \\
\hline Time in sedentary activity (actical) (min/d) & $1098.1 \pm 99.2$ & $1092.8 \pm 99.8$ & $1103.0 \pm 98.6$ \\
\hline Time in light activity (actical) (min/d) & $206.9 \pm 59.8$ & $204.1 \pm 59.3$ & $209.6 \pm 60.3$ \\
\hline Time in moderate activity (actical) (min/d) & $131.2 \pm 51.7$ & $138.7 \pm 53.3^{\psi}$ & $124.1 \pm 49.2$ \\
\hline Time in vigorous activity (actical) (min/d) & $3.8 \pm 7.8$ & $4.3 \pm 8.6$ & $3.3 \pm 7.0$ \\
\hline Total self reported energy expenditure (MET*hr/wk) & $388.6 \pm 74.8$ & $381.9 \pm 77.5$ & $394.9 \pm 71.9$ \\
\hline
\end{tabular}

Men vs. women, $\gamma p<0.05,{ }^{\psi} p<0.01,{ }^{*} p<0.001$ 
Table 2 Measures of muscular strength and endurance for the total sample and by gender (Mean \pm SD)

\begin{tabular}{|c|c|c|c|}
\hline Measure & Total $(n=412)$ & Men $(n=198)$ & Women $(n=214)$ \\
\hline Handgrip strength (kg) & $39.1 \pm 12.8$ & $48.6 \pm 10.5^{*}$ & $30.3 \pm 7.1$ \\
\hline Isometric knee extension (peak torque-Nm) & $190.1 \pm 69.8$ & $235.6 \pm 63.4^{*}$ & $147.7 \pm 44.4$ \\
\hline Isometric knee flexion (peak torque-Nm) & $82.4 \pm 30.8$ & $103.7 \pm 26.6^{*}$ & $62.7 \pm 19.2$ \\
\hline Isokinetic knee extension $60^{\circ}$ /s (peak torque-Nm) & $146.9 \pm 52.6$ & $184.7 \pm 44.1^{*}$ & $112.1 \pm 31.5$ \\
\hline Isokinetic knee flexion $60^{\circ} / \mathrm{s}$ (peak torque-Nm) & $76.2 \pm 30.5$ & $97.6 \pm 23.4^{*}$ & $56.3 \pm 21.5$ \\
\hline Isokinetic knee extension $180^{\circ}$ /s (peak torque-Nm) & $99.6 \pm 38.9$ & $127.4 \pm 33.6^{*}$ & $74.0 \pm 22.1$ \\
\hline Isokinetic knee flexion 180\% /s (avg peak torque-Nm) & $54.3 \pm 22.3$ & $70.3 \pm 19.7^{*}$ & $39.5 \pm 14.0$ \\
\hline Knee endurance extension peak torque-Nm) & $84.7 \pm 31.2$ & $108.2 \pm 25.3^{*}$ & $63.2 \pm 17.5$ \\
\hline Knee endurance flexion (peak torque-Nm) & $46.0 \pm 17.8$ & $58.8 \pm 15.2^{*}$ & $34.1 \pm 10.3$ \\
\hline Fatigue index (\% decrease) & $31.0 \pm 8.5$ & $32.3 \pm 8.3^{\psi}$ & $29.8 \pm 8.5$ \\
\hline Isometric elbow extension (peak torque-Nm) & $44.1 \pm 20.4$ & $59.6 \pm 18.1^{*}$ & $29.6 \pm 8.1$ \\
\hline Isometric elbow flexion (peak torque-Nm) & $51.4 \pm 20.2$ & $67.9 \pm 15.5^{*}$ & $35.9 \pm 8.2$ \\
\hline Isokinetic elbow extension $60^{\circ}$ /s (peak torque-Nm) & $39.1 \pm 14.9$ & $51.0 \pm 11.8^{*}$ & $28.1 \pm 6.9$ \\
\hline Isokinetic elbow flexion $60^{\circ} / \mathrm{s}$ (peak torque-Nm) & $34.4 \pm 14.1$ & $46.8 \pm 9.2^{*}$ & $22.8 \pm 4.8$ \\
\hline Isokinetic elbow extension $180^{\circ}$ /s (avg peak torque-Nm) & $32.5 \pm 20.5$ & $43.1 \pm 24.9^{*}$ & $22.6 \pm 5.7$ \\
\hline Isokinetic elbow flexion 180\% /s (peak torque-Nm) & $30.1 \pm 11.4$ & $39.7 \pm 8.5^{*}$ & $21.2 \pm 4.4$ \\
\hline
\end{tabular}

Men vs. women, $\gamma p<0.05,{ }^{*} p<0.01,{ }^{*} p<0.001$

Table 3 Multivariate models of correlates of lower body muscle strength among STOMP participants $(n=412)$

\begin{tabular}{|c|c|c|c|c|c|c|}
\hline Muscle strength & Predictors & $\beta$ & $\mathrm{T}$ & Partial $r$ & $r^{2}$ & $\mathbf{p}$ \\
\hline \multirow[t]{4}{*}{ Isometric knee extension } & Gender & -0.574 & -16.363 & -0.634 & & $<0.001$ \\
\hline & Age & -0.342 & -9.919 & -0.445 & & $<0.001$ \\
\hline & $\mathrm{BMI}$ & 0.185 & 5.248 & 0.254 & & $<0.001$ \\
\hline & Time in sedentary behavior (min/day) & -0.097 & -2.809 & -0.139 & & 0.005 \\
\hline Model summary & & & & & 0.527 & $<0.001$ \\
\hline \multirow[t]{4}{*}{ Isokinetic knee extension $60 \%$ s } & Gender & -0.606 & -19.295 & -0.695 & & $<0.001$ \\
\hline & Age & -0.404 & -13.560 & -0.562 & & $<0.001$ \\
\hline & $\mathrm{BMI}$ & 0.155 & 5.022 & 0.244 & & $<0.001$ \\
\hline & Total energy expenditure (kcal/day) & 0.099 & 3.052 & 0.151 & & 0.002 \\
\hline Model summary & & & & & 0.656 & $<0.001$ \\
\hline \multirow[t]{4}{*}{ Isokinetic knee extension $180^{\circ} / \mathrm{s}$} & Gender & -0.618 & -18.581 & -0.682 & & $<0.001$ \\
\hline & Age & -0.361 & -11.430 & -0.497 & & $<0.001$ \\
\hline & $\mathrm{BMI}$ & 0.106 & 3.230 & 0.160 & & 0.001 \\
\hline & Total energy expenditure (kcal/day) & 0.101 & 2.941 & 0.146 & & 0.001 \\
\hline Model summary & & & & & 0.615 & $<0.001$ \\
\hline \multirow[t]{4}{*}{ Knee endurance extension } & Gender & -0.651 & -24.225 & -0.772 & & $<0.001$ \\
\hline & Age & -0.451 & -17.658 & -0.663 & & $<0.001$ \\
\hline & $\mathrm{BMI}$ & 0.146 & 5.511 & 0.266 & & $<0.001$ \\
\hline & Total energy expenditure (kcal/day) & 0.088 & 3.181 & 0.157 & & 0.002 \\
\hline Model summary & & & & & 0.748 & $<0.001$ \\
\hline
\end{tabular}

$B M I$ body mass index

total self reported energy expenditure $(\mathrm{p}=0.062)$. Factors accounting for $72.0 \%$ of the variance in isometric elbow extension were gender $(\mathrm{p}<0.001)$, age $(\mathrm{p}<0.001)$, BMI $(\mathrm{p}<0.001)$, and total self reported energy expenditure $(\mathrm{p}=0.051)$. Factors accounting for $72.0 \%$ of the variance in isokinetic elbow flexion at $60 \%$ s were gender $(\mathrm{p}<0.001)$, BMI $(\mathrm{p}<0.001)$, age $(\mathrm{p}<0.001)$, and total self reported energy expenditure $(\mathrm{p}=0.019)$. Factors accounting for $68.0 \%$ of the variance in isokinetic elbow extension at $60 \%$ s were gender $(\mathrm{p}<0.001)$, age 
Table 4 Multivariate models of correlates of upper body muscle strength among STOMP Participants $(n=412)$

\begin{tabular}{|c|c|c|c|c|c|c|}
\hline Muscle strength & Predictors & $\beta$ & $\mathrm{t}$ & Partial $r$ & $r^{2}$ & $\mathrm{p}$ \\
\hline \multirow[t]{3}{*}{ Handgrip strength } & Gender & -0.715 & -21.413 & -0.731 & & $<0.001$ \\
\hline & Age & -0.187 & -5.590 & -0.269 & & $<0.001$ \\
\hline & Time in light intensity activity (min/day) & 0.127 & 3.784 & 0.186 & & $<0.001$ \\
\hline Model summary & & & & & 0.552 & $<0.001$ \\
\hline \multirow[t]{4}{*}{ Isokinetic elbow flexion $60 \% \mathrm{~s}$} & Gender & -0.824 & -33.748 & -0.861 & & $<0.001$ \\
\hline & BMI & 0.155 & 6.307 & 0.301 & & $<0.001$ \\
\hline & Age & -0.145 & -6.032 & -0.289 & & $<0.001$ \\
\hline & Time in light intensity activity (min/day) & 0.074 & 3.085 & 0.153 & & 0.002 \\
\hline Model summary & & & & & 0.772 & $<0.001$ \\
\hline
\end{tabular}

BM body mass index

Table 5 Multivariate models of correlates of lower body muscle strength among STOMP participants $(n=412)$

\begin{tabular}{|c|c|c|c|c|c|c|}
\hline Muscle strength & Predictors & $\beta$ & $\mathbf{t}$ & Partial $r$ & $r^{2}$ & $\mathrm{p}$ \\
\hline \multirow[t]{4}{*}{ Isometric knee extension } & Gender & -0.589 & -16.959 & -0.645 & & $<0.001$ \\
\hline & Age & -0.354 & -10.333 & -0.457 & & $<0.001$ \\
\hline & $\mathrm{BMI}$ & 0.178 & 5.073 & 0.245 & & $<0.001$ \\
\hline & Total self reported energy expenditure (MET*hr/wk) & 0.074 & 2.145 & 0.106 & & 0.033 \\
\hline Model summary & & & & & 0.530 & $<0.001$ \\
\hline \multirow[t]{4}{*}{ Isometric knee flexion } & Gender & & & -0.704 & & $<0.001$ \\
\hline & Age & & & -0.547 & & $<0.001$ \\
\hline & BMI & & & 0.171 & & 0.001 \\
\hline & Total self reported energy expenditure (MET*hr/wk) & & & 0.127 & & 0.010 \\
\hline Model summary & & & & & 0.606 & $<0.001$ \\
\hline
\end{tabular}

$B M I$ body mass index

( $\mathrm{p}<0.001)$, BMI $(\mathrm{p}<0.001)$, and total self reported energy expenditure $(\mathrm{p}=0.045)$. Factors accounting for $67.9 \%$ of the variance in isokinetic elbow flexion at $180^{\circ} / \mathrm{s}$ were gender $(\mathrm{p}<0.001)$, BMI $(\mathrm{p}<0.001)$, age $(\mathrm{p}<0.001)$, and total self reported energy expenditure $(\mathrm{p}=0.062)$.

In every model, gender was the strongest predictor of muscle strength $(r=-0.861$ to -0.645$)$, followed by either age ( $\mathrm{r}=-0.547$ to -0.241$)$ or BMI $(r=0.134-$ 0.397 ), and last physical activity as measured by the Paffenbarger physical activity questionnaire $(r=0.093-$ 0.127). Season, test site, and $\mathrm{VO}_{2 \max }$ were not significant correlates of upper and lower body muscle strength $(\mathrm{p}>0.05)$.

\section{Discussion}

The primary purpose of this STOMP sub-study was to provide insight into discrepant reports in the literature on the relationship between physical activity and muscle strength across the lifespan. Accordingly, we assessed the relationships among self-report and objective measures of habitual physical activity as they correlated with upper and lower body measures of muscle strength, as well as other factors that have been reported to influence these relationships, among a large cohort of approximately equal numbers of healthy, men and women from 20 to 91 years. Overall, the strongest correlates of upper and lower body muscle strength were gender accounting for $40-74 \%$, age $6-44 \%$, and BMI $2-16 \%$ of the variance; whereas, physical activity correlations were much weaker explaining $1-3 \%$ of the variance. Of note is that season, test site, and $\mathrm{VO}_{2 \max }$ did not emerge as significant covariates in these models ( $p>0.05)$. Last, self-report measures of physical activity correlated more strongly with upper body strength measures, while objective measures of physical activity correlated more strongly with lower body strength measures. Our study demonstrated that the contributions of gender, age, and BMI in explaining the individual variability in muscle strength superseded those of physical activity. They also suggest that habitual physical activity may not be effective to reduce age and disease related declines in muscle strength (American College of Sports Medicine, 2013), p 210.

It has been well documented that men are stronger than women (Musselman and Brouwer 2005), muscle strength declines with age (Rogers and Evans 1993), and absolute muscle strength increases with body size 
Table 6 Multivariate models of correlates of upper body muscle strength among STOMP participants $(n=412)$

\begin{tabular}{|c|c|c|c|c|c|c|}
\hline Muscle strength & Predictors & $\beta$ & $\mathrm{t}$ & Partial $r$ & $r^{2}$ & $\mathrm{p}$ \\
\hline \multirow[t]{4}{*}{ Handgrip strength } & Gender & -0.697 & -20.613 & -0.716 & & $<0.001$ \\
\hline & Age & -0.201 & -6.023 & -0.287 & & $<0.001$ \\
\hline & BMl & 0.093 & 2.720 & 0.134 & & $<0.01$ \\
\hline & Total self reported energy expenditure (MET*hr/wk) & 0.062 & 1.868 & 0.093 & & 0.062 \\
\hline Model summary & & & & & 0.554 & $<0.001$ \\
\hline \multirow[t]{4}{*}{ Isometric elbow extension } & Gender & -0.679 & -23.089 & -0.754 & & $<0.001$ \\
\hline & Age & -0.290 & -9.979 & -0.445 & & $<0.001$ \\
\hline & BMl & 0.257 & 8.685 & 0.397 & & $<0.001$ \\
\hline & Total self reported energy expenditure (MET*h/wk) & 0.57 & 1.954 & 0.097 & & 0.051 \\
\hline Model summary & & & & & 0.720 & $<0.001$ \\
\hline \multirow[t]{4}{*}{ Isokinetic elbow flexion $60 \%$ s } & Gender & -0.827 & -34.042 & -0.861 & & $<0.001$ \\
\hline & $\mathrm{BMI}$ & 0.153 & 6.245 & 0.297 & & $<0.001$ \\
\hline & Age & -0.147 & -6.124 & -0.291 & & $<0.001$ \\
\hline & Total self reported energy expenditure (MET*hr/wk) & 0.056 & 2.345 & 0.116 & & 0.019 \\
\hline Model summary & & & & & 0.720 & $<0.001$ \\
\hline \multirow[t]{4}{*}{ Isokinetic elbow extension $60 \%$ s } & Gender & -0.726 & -25.353 & -0.784 & & $<0.001$ \\
\hline & Age & -0.281 & -9.938 & -0.443 & & $<0.001$ \\
\hline & BMl & 0.182 & 6.315 & 0.300 & & $<0.001$ \\
\hline & Total self reported energy expenditure (MET*hr/wk) & 0.057 & 2.012 & 0.100 & & 0.045 \\
\hline Model summary & & & & & 0.680 & $<0.001$ \\
\hline \multirow[t]{4}{*}{ Isokinetic elbow flexion $180 \%$ s } & Gender & -0.774 & -26.978 & -0.802 & & $<0.001$ \\
\hline & $\mathrm{BMI}$ & 0.152 & 5.274 & 0.254 & & $<0.001$ \\
\hline & Age & -0.141 & -4.998 & -0.241 & & $<0.001$ \\
\hline & Total self reported energy expenditure (MET*hr/wk) & 0.053 & 1.875 & 0.093 & & 0.062 \\
\hline Model summary & & & & & 0.679 & $<0.001$ \\
\hline
\end{tabular}

BMlbody mass index

(Hortobagyi et al. 1990). However, this is the first study to the best of our knowledge, to examine the contribution of each of these factors individually in conjunction with self- report and objective measures of habitual physical activity in explaining the variability in muscle strength and endurance among a large group of healthy men and women. Presently, the literature is mixed regarding the relationship between physical activity and muscle strength partially due to the methods used to assess physical activity and the population examined (Bryant et al. 2007; Daly et al. 2008; Forrest et al. 2007; Gerdhem et al. 2008; Jakobsen et al. 2010; Morie et al. 2010; Paalanne et al. 2009; Rantanen et al. 1997; Sandler et al. 1991). We found that the contributions of gender, age, and BMI were significantly greater than those of physical activity, regardless of the method of physical activity assessment; findings that further lend insight into reasons for mixed reports in this literature.

Consistent with our findings, a number of investigative teams have found self-reported physical activity to be associated with isometric or isokinetic muscle strength of the upper or lower body in adults across the lifespan
(Forrest et al. 2007; Jakobsen et al. 2010; Paalanne et al. 2009; Rantanen et al. 1997; Sandler et al. 1991). Amongst these studies, only one (Sandler et al. 1991) examined additional factors that may have contributed to variations in muscle strength as measured isometrically via custom made devices for the extremities and isokinetically via the Cybex for trunk musculature, and found age was the strongest predictor of muscle strength, followed by either physical activity or body weight. The population studied by Sandler et al. (Sandler et al. 1991) included 620 healthy women from 25 to $55+$ years, but their findings cannot be generalized to men. In contrast to these findings and ours, other studies have reported no correlation between self-reported physical activity and any measure of muscle strength among samples that included older adults age $50+$ years (Bryant et al. 2007; Daly et al. 2008) suggesting that the older age of the populations in these studies may have obscured the influence of physical activity on muscle strength.

A unique aspect of our study is that we used both selfreport and objective measures of physical activity to profile the multidimensional nature of physical activity (D. 
Thompson, Peacock, Western, and Batterham 2015). We found similar weak associations using both a self-report questionnaire and an accelerometer to measure physical activity and muscle strength $(r=0.139-0.186)$; findings which contrast the small body of literature utilizing an accelerometer to examine these relationships (Gerdhem et al. 2008; Morie et al. 2010). A possible explanation for the discrepancies between these findings and ours is that Gerdhem et al. (2008) and Morie et al. (2010) included only older adults of one gender (Gerdhem et al. 2008; Morie et al. 2010), whereas we examined both genders in healthy adults across the lifespan. In addition, the sample size of both of these other studies was small $(n=57-82)$ which may not have provided the power needed to capture the weak associations between physical activity and muscle strength that we found to be superseded by the stronger effects of gender, age, and BMI.

Another unanticipated finding of our study was that self-reported physical activity measured by the Paffenbarger Questionnaire correlated more strongly with measures of upper body strength, while physical activity measured with an accelerometer correlated more strongly with measures of lower body strength. A possible explanation for these differential associations of selfreport versus objectively measured physical activity with muscle strength is an accelerometer worn on the hip, as opposed to self-reported physical activity, is most sensitive to recording movement in the vertical plane (Wolin, Heil, Askew, Matthews, and Bennett 2008). Movement in the vertical plane typically occurs more during lower body than upper body physical activities. Thus, our results support using multiple methods to assess the multidimensional aspects of physical activity (D. Thompson et al. 2015).

\section{Potential study limitations}

There were limitations to this study. The study design of STOMP (P. D. Thompson et al. 2010) was not specifically designed to measure the relationship between physical activity and muscle strength among healthy adults across the lifespan. This STOMP sub-study was cross-sectional as opposed to a longitudinal intervention, and thus we can only comment on association rather than causation. The larger STOMP study was conducted among multiple sites that may have contributed to variations in procedures and equipment among the sites. Nevertheless, all sites followed a strict set of standard operating procedures, and monthly research meetings were held to monitor all progress to ensure consistency among the involved sites. Finally, the sample was not truly random; rather it was self-selected because only people who met the exclusion criteria and were willing to take a clinical drug for 6 months agreed to participate in the study.

\section{Study strengths}

On the other hand, this study has several strengths. Perhaps one of the most important is that this study is distinguished from previous research by using multidimensional measurements of both physical activity and muscle strength. In addition, the sample size was large and encompassed all adult ages, as well as having equal numbers of men and women, allowing for sufficient statistical power to test for associations between physical activity and muscle strength, using gender, age, and BMI as covariates.

\section{Conclusions and practical applications}

The major findings of this study were that physical activity explained only $1-3 \%$ of the variance in muscle strength; whereas gender explained $40-74 \%$, age 6-44\%, and BMI $2-16 \%$ of the variance. In total, these models explained $53-77 \%$ of the variance in muscle strength. Second, self-reported physical activity correlated with more strongly with measures of upper body strength, while objective measures of physical activity correlated with more strongly with measures of lower body strength.

In addition to providing clinicians with an overall picture of the important contributors to muscle strength across the lifespan, our findings provide insight into the discrepancies in this literature. Of import is that health care and exercise professionals should consider using multiple measures of physical activity and muscle strength and carefully consider the age and gender of the populations they employ to assess these relationships in their studies. Future studies may consider investigating these relationships in disease populations, as the contribution of physical activity to muscle strength may differ significantly from the healthy adult population.

In summary, although physical activity correlations with muscle strength appear weak indicating that habitual physical activity may not be effective at reducing age and disease related declines in muscle strength, maintaining a physical active lifestyle is crucial to healthy aging due to its many health benefits (US Department of Health and Human Services 2008).

\section{Abbreviations}

BMI: body mass index; STOMP: the effect of statins on skeletal muscle function; MET: metabolic equivalent task.

\section{Authors' contributions}

$\mathrm{AL}$ was involved in the data collection and data entry at both the University of Connecticut and Hartford Hospital test sites from 2009 to 2011, and then completed the entire data analysis, drafting, and revision of this manuscript. She has also given final approval for submission. LP, BT, PT, CW, PC, and JC were involved in the writing and submission of the grant to $\mathrm{NIH}$ for funding of this study, the design, data collection and data analysis of the STOMP study. LP and BT assisted in the revision of this manuscript. All authors read and approved the final manuscript. 


\section{Author details}

${ }^{1}$ University of Connecticut, 2095 Hillside Rd Unit 1110, Storrs, CT 06269, USA. ${ }^{2}$ University of Massachusetts, 110 Totmann Building, 30 Eastman Lane, Amherst, MA 01003, USA. ${ }^{3}$ Division of Cardiology, Henry Low Heart Center, Hartford Hospital, 80 Seymour St, Hartford, CT 06102, USA. ${ }^{4} 31$ Silversmith Rd, Unionville, CT 06085, USA.

\section{Author's information}

AL is a Doctor of Physical Therapy who was involved in this research for her undergraduate and graduate research projects at the University of Connecticut. LP is a professor in the Department of Kinesiology at the University of Connecticut and a fellow of the American College of Sports Medicine, and an expert in the field of cardiovascular pathology, hypertension, exercise, and aging. BT is the director of Exercise Physiology Research at Hartford Hospital and Director of the Center for Health, Care, and Well-Being in the Institute for Translational Research at Hartford Hospital, as well as an expert in the field of cardiovascular disease and health systems. JP is an exercise physiologist and study coordinator for the STOMP study at Hartford Hospital. PC was a distinguished professor of Kinesiology at the University of Massachusetts, Amherst and fellow of the American College of Sports Medicine, and nationally recognized researcher in muscle function. CW is a Doctor of Pharmacy and professor at the University of Connecticut, and considered an expert cardiac therapeutics. PT is a Doctor of Medicine and Cardiology at Hartford Hospital, medical director of "The Athlete's Heart Program", a fellow and past president of the American College of Sports Medicine and an expert in the effects of exercise training on preventing and treating heart disease.

\section{Acknowledgements}

I would like to acknowledge the entire STOMP team for their dedicated hard work in conceiving, designing, and acquiring the data for the STOMP study, from which this sub-study was conceived. I would also like to acknowledge Dr. Linda Pescatello and Dr. Beth Taylor who were instrumental in revisions of this manuscript. The funding for the STOMP study was provided by the National Institute of Health, and there was no funding for the writing of this manuscript.

\section{Competing interests}

The authors declare that they have no competing interests.

Received: 8 July 2015 Accepted: 21 September 2015

Published online: 28 September 2015

\section{References}

American College of Sports Medicine (Ed). (2013). ACSM's guidelines for exercise testing and prescription. 9th edn. LWW

Balke B, Ware RW (1959) An experimental study of physical fitness of air force personnel. United States Armed Forces Med J 10(6):675-688

Ballard KD, Parker BA, Capizzi JA, Grimaldi AS, Clarkson PM, Cole SM, Thompson PD (2013) Increases in creatine kinase with atorvastatin treatment are not associated with decreases in muscular performance. Atherosclerosis 230(1):121-124. doi:10.1016/j.atherosclerosis.2013.07.001

Bosco C, Komi PV (1980) Influence of aging on the mechanical behavior of leg extensor muscles. Eur J Appl Physiol 45(2-3):209-219

Bryant EC, Trew ME, Bruce AM, Cheek L (2007) Lower limb muscle strength and physical activity in healthy individuals approaching retirement. J Sports Sci 25(7):835-842. doi:10.1080/02640410600875077

Daly RM, Ahlborg HG, Ringsberg K, Gardsell P, Sernbo I, Karlsson MK (2008) Association between changes in habitual physical activity and changes in bone density, muscle strength, and functional performance in elderly men and women. J Am Geriatr Soc 56(12):2252-2260. doi:10.1111/j.1532-5415.2008.02039.x

Forrest KY, Zmuda JM, Cauley JA (2007) Patterns and correlates of muscle strength loss in older women. Gerontology 53(3):140-147. doi:10.1159/000097979

Gerdhem P, Dencker M, Ringsberg K, Akesson K (2008) Accelerometer-measured daily physical activity among octogenerians: results and associations to other indices of physical performance and bone density. Eur J Appl Physiol 102(2):173-180. doi:10.1007/s00421-007-0571-z
Goodpaster BH, Park SW, Harris TB, Kritchevsky SB, Nevitt M, Schwartz AV, Newman $A B$ (2006) The loss of skeletal muscle strength, mass, and quality in older adults: the health, aging and body composition study. J of Gerontol Ser A Biol Sci Med Sci 61(10):1059-1064

Grimaldi AS, Parker BA, Capizzi JA, Clarkson PM, Pescatello LS, White MC, Thompson PD (2013) 25(OH) vitamin D is associated with greater muscle strength in healthy men and women. Med Sci Sports Exerc 45(1):157162. doi:10.1249/MSS.0b013e31826c9a78

Hollmann W, Struder HK, Tagarakis CV, King G (2007) Physical activity and the elderly. European J Cardiovasc Prev Rehabilitation Off J European Soc Cardiol Work Groups Epidemiol Prev Cardiac Rehabilitation Exerc Physiol 14(6):730-739. doi:10.1097/HJR.0b013e32828622f9

Hortobagyi T, Katch Fl, Katch VL, LaChance PF, Behnke AR (1990) Relationships of body size, segmental dimensions, and ponderal equivalents to muscular strength in high-strength and low-strength subjects. Int J Sports Med 11(5):349-356

Jakobsen LH, Rask IK, Kondrup J (2010) Validation of handgrip strength and endurance as a measure of physical function and quality of life in healthy subjects and patients. Nutrition (Burbank, Los Angeles County, Calif.) 26(5):542-550. doi:10.1016/j.nut.2009.06.015

Kallman DA, Plato CC, Tobin JD (1990) The role of muscle loss in the agerelated decline of grip strength: cross-sectional and longitudinal perspectives. J Gerontol 45(3):M82-M88

Morie M, Reid KF, Miciek R, Lajevardi N, Choong K, Krasnoff JB, Lebrasseur NK (2010) Habitual physical activity levels are associated with performance in measures of physical function and mobility in older men. J Am Geriatr Soc 58(9):1727-1733. doi:10.1111/j.1532-5415.2010.03012.x

Musselman K, Brouwer B (2005) Gender-related differences in physical performance among seniors. J Aging Phys Activity 13(3):239-253

Paalanne NP, Korpelainen RI, Taimela SP, Auvinen JP, Tammelin TH, Hietikko TM, Karppinen J (2009) Muscular fitness in relation to physical activity and television viewing among young adults. Med Sci Sports Exerc 41(11):1997-2002. doi:10.1249/MSS.0b013e3181a7f3a6

Paffenbarger RS Jr, Wing AL, Hyde RT (1978) Physical activity as an index of heart attack risk in college alumni. Am J Epidemiol 108(3):161-175

Parker BA, Capizzi JA, Grimaldi AS, Clarkson PM, Cole SM, Keadle J, Thompson PD (2013) Effect of statins on skeletal muscle function. Circulation 127(1):96-103. doi:10.1161/CIRCULATIONAHA.112.136101

Pincivero DM, Campy RM, Coelho AJ (2003) Knee flexor torque and perceived exertion: a gender and reliability analysis. Med Sci Sports Exerc 35(10):1720-1726. doi:10.1249/01.MSS.0000089246.90005.47

Rantanen T, Era P, Heikkinen E (1997) Physical activity and the changes in maximal isometric strength in men and women from the age of 75-80 years. J Am Geriatr Soc 45(12):1439-1445

Rogers MA, Evans WJ (1993) Changes in skeletal muscle with aging: effects of exercise training. Exerc Sport Sci Rev 21:65-102

Sandler RB, Burdett R, Zaleskiewicz M, Sprowls-Repcheck C, Harwell M (1991) Muscle strength as an indicator of the habitual level of physical activity. Med Sci Sports Exerc 23(12):1375-1381

Stroes ES, Thompson PD, Corsini A, Vladutiu GD, Raal FJ, Ray KK, European Atherosclerosis Society Consensus Panel (2015) Statin-associated muscle symptoms: impact on statin therapy-european atherosclerosis society consensus panel statement on assessment, aetiology and management. Eur Heart J [pii] ehv043

Takken T, Blank AC, Hulzebos EH, van Brussel M, Groen WG, Helders PJ (2009) Cardiopulmonary exercise testing in congenital heart disease: equipment and test protocols. Neth Heart J Mon J Neth Soc Cardiol Neth Heart Found 17(9):339-344

Thompson PD, Parker BA, Clarkson PM, Pescatello LS, White CM, Grimaldi AS, Hoffman EP (2010) A randomized clinical trial to assess the effect of statins on skeletal muscle function and performance: rationale and study design. Prev Cardiol 13(3):104-111. doi:10.1111/j.1751-7141.2009.00063.x

Thompson D, Peacock O, Western M, Batterham AM (2015) Multidimensional physical activity: an opportunity, not a problem. Exerc Sport Sci Rev 43(2):67-74. doi:10.1249/JES.0000000000000039

US Department of Health and Human Services. (2008). Physical activity guidelines for Americans. Atlanta, Georgia: US Department of Health and Human Services, Public Health Service, CDC, National Center for Chronic Disease Prevention and Health Promotion

Wolin KY, Heil DP, Askew S, Matthews CE, Bennett GG (2008) Validation of the international physical activity questionnaire-short among blacks. J Phys Activity Health 5(5):746-760 